\title{
UNVEILING THE CO-WORD STRUCTURES AMONG MOBILE COMPUTING, MOBILE COMMERCE AND MOBILE APPLICATION RESEARCH: A SCIENCE MAPPING ANALYSIS
}

\author{
Hsia-Ching Chang \\ University of North Texas \\ 1155 Union Circle \#311277, Denton, Texas 76203 \\ Hsia-Ching.Chang@unt.edu \\ Chen-Ya Wang \\ National Open University \\ 172 Zhongzheng Rd., Luzhou Dist., New Taipei City 247, Taiwan \\ ntuimgrace@gmail.com
}

\begin{abstract}
While various topics in mobile computing, commerce and applications have been extensively investigated, the co-occurrences of keywords in the relevant studies remain relatively unexplored. This study performs a co-word analysis, a widely adopted method of science mapping in scientometrics, for a corpus of $4821 \mathrm{SCI} / \mathrm{SSCI}$ indexed papers related to mobility in the Web of Science (WoS) database from 1995 to 2013. The results reveal the interplay over time among mobile computing, commerce and applications. The emerging concepts demonstrated in the strategic diagrams and the associated co-word structures have implications for researchers who are tracking the topics which might gain ground over the next few years.
\end{abstract}

Keywords: Mobile Computing, Mobile Commerce, Mobile Applications, Co-word Analysis, Scientometrics

\section{INTRODUCTION}

Mobile space is characterized by uncertainty of future standards and evolving computing environment. On one hand, the age of advanced mobile technology has created numerous possibilities for enriching the future convergence of computing environments. On the other hand, due to their inherent uncertainty and complexity, many studies have been concerned with the difficulties of developing mobile applications. The results of bibliometric studies could prove useful to researchers in regard to the 
important topics and work in certain fields ${ }^{1}$. However, there have been few studies in the use of bibliometric methods in mobile computing, not to mention longitudinal studies. Based on bibliometric methods, science mapping analysis with a longitudinal perspective in scientometrics may lead to a deeper understanding of topic evolutions in any domain, thereby contributing to our understanding of how, and to what extent, research topics have emerged and evolved. Keywords assigned by authors are useful for uncovering the relationships among papers in terms of scientific developments and changes ${ }^{2}$. Co-word analysis ${ }^{3}$, a method of science mapping in scientometrics, identifies associations among the indexing terms used in publications. The sources of indexing terms come from both authors' keywords and publishers' classification indices (e.g., WoS Keyword Plus), which produce networks of keywords revealing the underlying patterns of research themes. This paper is divided into five sections. Section one briefly introduces the purpose of our research. Section two outlines the related work in science mapping and trends in mobility. Section three discusses the research design and methods. Section four presents the analysis and visualization results. Finally, section five suggests the implications.

\section{RELATED WORK}

\subsection{Science Mapping Studies}

Science mapping studies entail both macro- and micro-level perspectives ${ }^{4}$. Macro-level studies emphasize science policy decision-making by evaluating scientometric indicators of research efforts, either nationally or institutionally. Those studies aim to inform science and technology management by visualizing domain distribution ${ }^{4}$ and locating research activity among or across the disciplines for policy management ${ }^{5}$. In contrast, micro-level studies focus on research specialty ${ }^{6}$, especially interdisciplinary fields ${ }^{7}$. Strategically speaking, science mapping can be a roadmap for technology foresight methods ${ }^{8}$, which present the trajectories of the essential scientific discoveries from journals and conference proceedings over time.

\subsection{Recent Trends in Mobile Computing}

The next decade of mobile computing systems will encounter competing design challenges between wireless connectivity and resource tradeoff of mobile devices. Though $4 \mathrm{G}$ connectivity has wider coverage, it might be accompanied by poorer bandwidth in certain locations, like inside buildings. Future architectures for mobile computing are likely to extend from a two-level (client-server or client-cloud) to a three-level hierarchy, for example, a new layer (i.e. cloudlet) between the local client and the remote server (or cloud) would be deployed ${ }^{9}$. With a focus on design science, 
Andersson ${ }^{10}$ selected 102 papers on mobile computing published in 26 journals between 1999 and 2008. Those papers were classified based on the accentuated factors of mobile computing, research approach (descriptive or prescriptive) and use scenario (B2E/B2B, B2C/C2C, or Technical/Neutral). The results showed that most articles stressed factors such as context awareness (25.4\%), interface (21.5\%), varying connectivity (13.8\%) and hardware capacities $(9.8 \%)$. Although publications accounting for technical issues of mobile computing from computer science fields were excluded, the author mentioned the under-researched factors in application dependencies, supporting technologies, task dependencies and time dependencies. Recent studies of the potential effectiveness of mobile computing integrate a variety of computing environments, such as cloud computing ${ }^{11,}{ }^{12}$, social networking ${ }^{13}$, and big data computing ${ }^{11}$. Hsieh, Li and Yang ${ }^{11}$ suggested that combining mobile computing with strategic use of storage-as-a-service cloud computing would resolve storage issues and contribute to big data analytics.

\subsection{Recent Trends in Mobile Commerce}

Early classifications of mobile commerce studies can be traced to Varshney \& Vetter ${ }^{14}$ and Mennecke \& Strader ${ }^{15}$, which focused on supporting technology, such as m-commerce applications, wireless user infrastructure, mobile middleware, and wireless network infrastructure. Based on the classification schemes, Ngai and Gunasekaran ${ }^{16}$ added "m-commerce theory and research" to the proposed scheme because the majority of articles $(43.09 \%)$ they collected fell into this category. Since Ngai and Gunasekaran ${ }^{16}$ collected articles of m-commerce-related published between 2000 and 2003 in multiple online databases, they analyzed 149 articles that had been published in the initial stage of m-commerce development. Additionally, the authors admitted that the identified categories in the classification merely rested on the authors' observations. In their literature review of the intersections of mobile commerce, mobile business and mobile marketing or advertising, Varnali and Toker ${ }^{17}$ found a dearth of empirical studies, particularly in the area of mobile marketing. Based on the journal-paper search in multiple online databases, Varnali and Toker ${ }^{17}$ reviewed 255 papers from 82 journals and proposed a classification framework for categorizing mobile marketing research. The classification framework they proposed encompasses theory (17.25\%), strategy (28.63\%), consumer behavior (51.37\%), and legal and public policy (3\%).

\subsection{Recent Trends in Mobile Applications}

The early big three mobile application platform providers and their market shares were Nokia's Symbian OS (46.6\%), Apple's iPhone OS $(17.3 \%)$ and RIM's Blackberry OS (15.2\%) ${ }^{18}$. Although Google's Android 
OS was launched later, Holzer and Ondrus ${ }^{18}$ predicted that it would soon become one of the big players in the marketplace. Three market and technology trends in mobile application development marketplace were indicated: portal centralization, technological openness and platform integration ${ }^{19}$. In addition, user experience plays an important role in mobile application development and adoption ${ }^{20}$, which underscores two primary aspects: the context (including device affordances, platform user interface conventions, and environments) and implementations (including performance, design and integration with platform features). The context cannot be controlled in a mobile application, but the implementation can ${ }^{20}$. As Emmanouilidis, Koutsiamanis and Tasidou ${ }^{21}$ highlighted, the potential causes of the complexity in mobile space consist of, for instance, the diversity of users, devices, platforms, networks, and functionality of applications.

\section{METHODOLOGY}

During the past thirty years, science mapping scholars have developed an impressive array of methods and tools for illustrating and measuring the evolution of science and technology. Garfield ${ }^{22}$ defined dynamic longitudinal mapping as "a series of chronologically sequential maps of science," which brought the notion of trend analysis to scientometrics and considered science maps as forecasting tools. Therefore, using science mapping software tools can reveal longitudinal trends through the analysis of bibliometric metadata in a specific research area.

\subsection{Research Design and Data}

This study answers the following research question: How can the Web of Science (WoS) database be used to identify and map research themes of mobile computing, commerce and applications over time? In an attempt to understand the evolution of shared research themes, this study performed co-word analysis using descriptor data (both authors' keywords and WoS Keywords Plus) and visualized the results with strategic diagrams ${ }^{23,24}$ in order to demonstrate positions of word clusters in the research domain. Using the science mapping tool, SciMAT 1.1.02 ${ }^{25}$, the co-word structures in mobile related research have been analyzed for four periods: 1995-1999, 2000-2004, 2005-2009 and 2010-2013. The measures of keyword networks were not only density and centrality ${ }^{24}$, but also impact metrics of topic keywords, such as counts of documents, and totals of citations. The keyword structures were presented with strategic diagrams and co-word networks. Furthermore, mobile computing technology and applications support the development of mobile commerce ${ }^{16}$. In mapping mobility research, it is necessary to take account of the related topics together. This study collected 
documents and their bibliometric metadata from the Web of Science (WoS) Science Citation Index (SCI)/Social Science Citation Index (SSCI) indexed articles consisting of three keywords: "mobile computing," "mobile commerce" and "mobile application(s)" in titles, abstracts, authors" keywords, or subject headings. Data collection took place in February 2014. Limited to journal papers, conference-related articles, book chapters and reviews, there are 4821 documents in total containing mobility-related keywords published from 1995 to 2013.

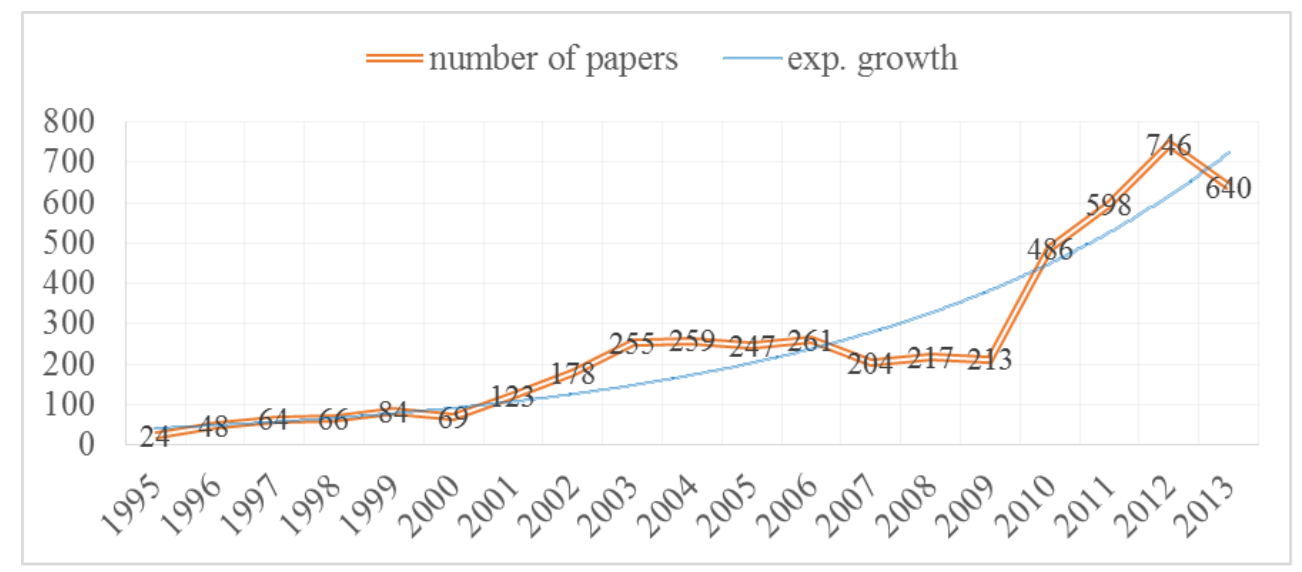

Figure 1. Yearly distribution of mobile computing and application papers

Fig. 1 shows the growth trend of mobile computing and application papers. It appears to follow a ten-year cycle from $2 \mathrm{G}$ to $3 \mathrm{G}$, and $3 \mathrm{G}$ to $4 \mathrm{G}$. Therefore, the milestones of exceeding the exponential growth occurred at the generation transitions of mobile communication standards. For instance, since 2000, the mobile standard has shifted from 2.5G to 3G; since 2009 or 2010, it has moved from $3.5 \mathrm{G}$ to $4 \mathrm{G}$. The rapid growth of mobile-related publications was consistently started by moving toward the new generations of mobile communication standards. According to the author keyword distribution, Fig. 2 depicts a clear relationship between mobile computing and the developments of mobile commerce and applications. It seems that while the number of mobile computing research rose, the number of mobile commerce and applications studies would follow up with a one- or two-year lag. Additionally, journal papers represent a major contribution $(53.7 \%)$ to the field of mobile computing and applications. However, for such field that is fast-moving technologically, proceeding papers may be considered a valuable contribution $(45 \%)$ because of the timeliness of conference proceedings. 


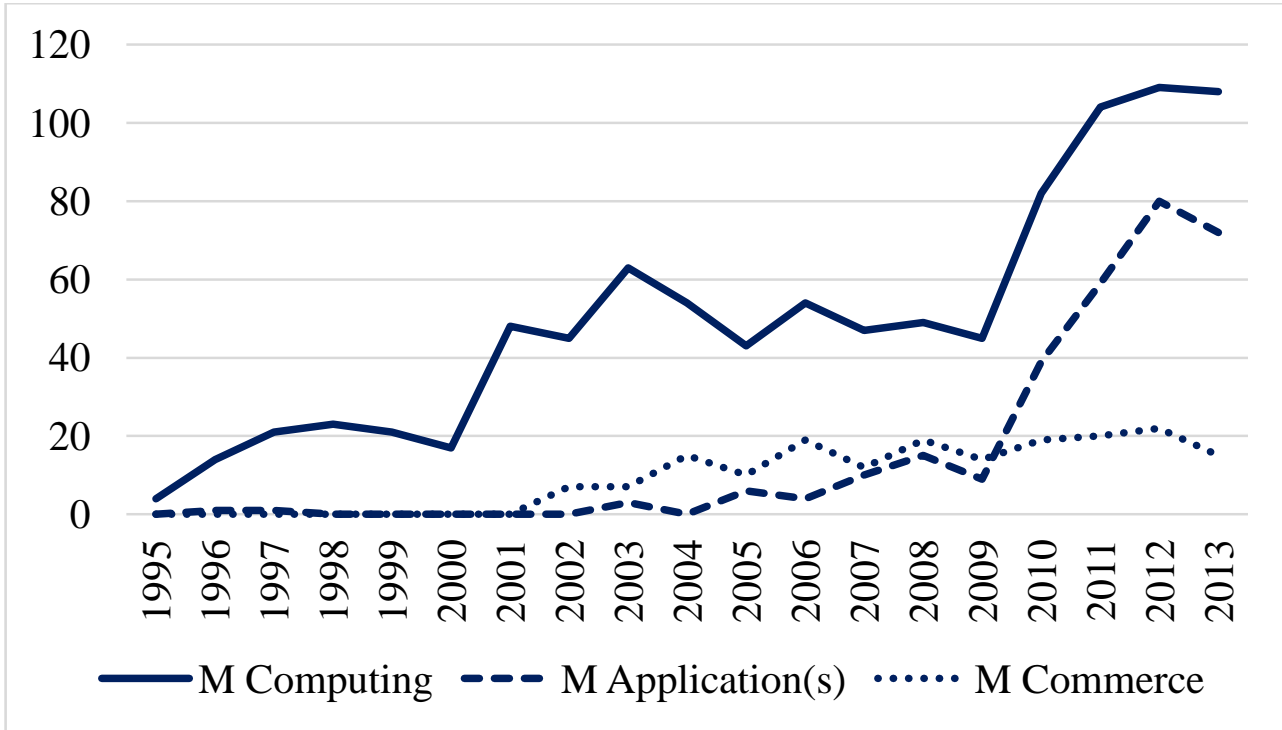

Figure 2. Yearly distribution of author keywords among mobility topics

Furthermore, among the six countries that are most active in mobile computing and applications research, the United States dominates the field, accounting for $23 \%$ of publications, followed by several Asian countries, China (9.8\%), South Korea (8.9\%) and Taiwan (7.8\%). Germany (6.8\%) and United Kingdom (5.3\%) are the only European countries on the list.

\subsection{Co-word Analysis}

Widely applied to multiple domains, co-word analysis was originally developed for mapping the structure and dynamics of scientific and technological knowledge domains ${ }^{24}$, and often served as a powerful tool for knowledge discovery. According to Callon et al. ${ }^{3}$, maps of co-word clusters can be generated and clusters can be positioned in the form of strategic diagrams based on the strengths of their internal links (measured by density) and external links (measured by centrality). Since the data output from the WoS database inevitably contain errors, this study cleaned the data by de-duplicating, fixing errors or filling in missing data, and grouping similar words (i.e. plurals and exchangeable terms) during the preprocessing stage.

In this study, the number of unique keywords and documents related to mobility in the four periods are displayed in Fig. 3. A total of 1652 keywords were analyzed in this study, which consisted of 776 unique keywords. The numbers of documents and keywords have increased more than fivefold over the four periods. These numbers are expected to continue increasing and attract more research efforts on mobility. 


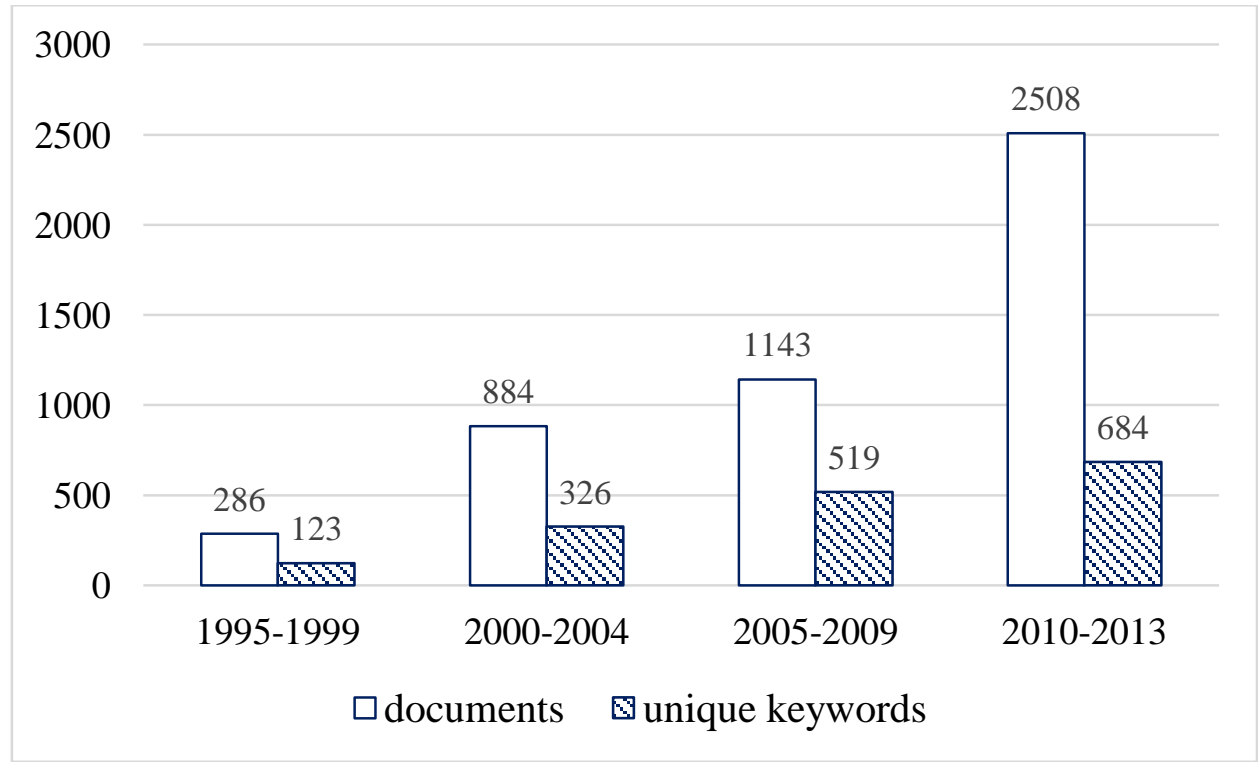

Figure 3. Distributions of the documents vs. unique keywords per period

\section{ANALYSIS RESULTS}

The central focus of research on certain topics is revealed by their authors' keyword choices. Therefore, authors' keywords have analytic significance that includes the research themes, methodology adopted, and conceptual models. SciMAT (Science Mapping Analysis software Tool), an open source science mapping software, incorporates algorithms and measures for all the processes involved in science mapping ${ }^{25}$. The clustering algorithm chosen to generate the strategic maps and its associated co-word networks in the SciMAT software is called simple centers algorithm and was originally proposed by Coulter, Monarch and Konda ${ }^{26}$. This section reports on the results of the keyword evolution in the longitudinal views of overlapping keyword map, strategic diagrams and co-word structures using SciMAT.

\subsection{Mapping Overlapping Keywords}

SciMAT has been designed to represent the keywords' transience and continuance over time in a graph. In Fig. 4, each circle presents each time period and the number inside each circle indicates the number of keywords in that period. The arrows connecting circles represent three types of keyword status. The two types of arrows on the top of circles refer to the amount of keywords that have not occurred and newly occurred in the sequential period. While the former is represented as an arrow pointing upwards out of the circle, the latter is represented as an arrow pointing 
downward toward the circle of the next period. In addition, the arrows connecting sequential periods indicate the number of keywords that are shared between periods; the number inside the parentheses is the similarity index.

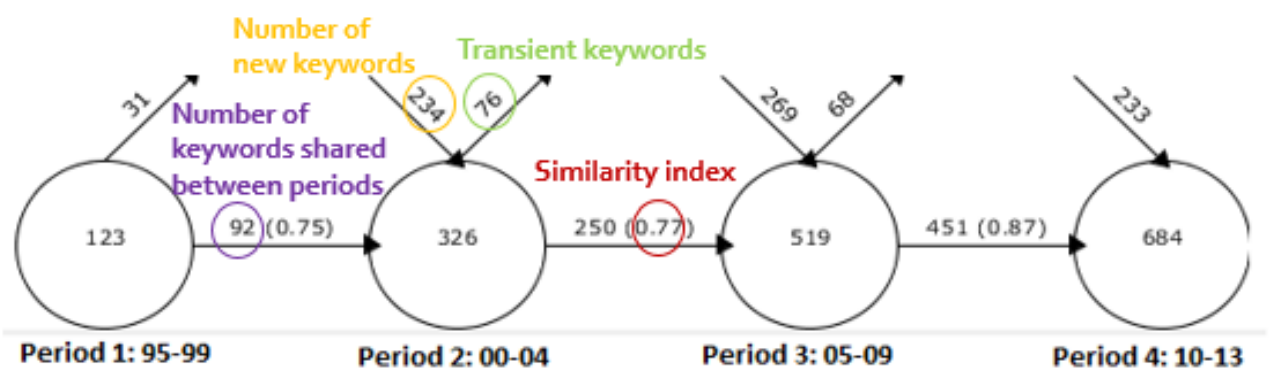

Figure 4. Overlapping keyword map

As shown in Fig. 4, there are 123, 326, 519 and 684 distinct keywords across four periods. The number of keywords in period 4 has grown fivefold compared to the number in the first period. Additionally, the number of newly introduced keywords seems higher than that of transient keywords. For example, 234, 269 and 233 new keywords respectively appear in period 2, period 3 and period 4, whereas there are only 31, 76 and 68 transient keywords respectively between periods. Furthermore, in the second period, there are 326 keywords in the paper collection, among which 250 keywords re-occur in the third period, while 76 keywords do not. The similarity index of keyword overlapping between periods 2 and 3 is 0.77 , growing from 0.75 between the first and second periods, and rising to 0.87 between periods 3 and 4. Although it remains to be seen if the number of transient keywords will decrease in the next period, it is evident that more than $70 \%$ of keywords remain constant between periods. These facts imply that the mobility research community increasingly reaches consensus on its terminology.

\subsection{Mapping Strategic Diagrams}

As demonstrated in Fig. 5, the strategic diagram (a two-dimensional graph) offers a representation of theme position based on two measures: centrality and density, identifying four quadrants of research development ${ }^{3}$. In the strategic diagrams, the three metrics listed in the bottom line of each sphere are document counts, total citations and h-index, corresponding to each theme. For the first period (1995-1999), there might be insufficient representative papers on mobile commerce and applications; therefore, mobile computing dominated mainstream research. The centrality of mobile computing greatly increased in the second period (2000-2004); however, the 
density score was approximately equal to the mean, locating it on the $\mathrm{x}$ axis between quadrants 1 and 4 . No topic located in the first quadrant during this period might result from the transition between $2 \mathrm{G}$ and $3 \mathrm{G}$. In addition, while PDA (25 papers) and design (24 papers) had a similar number of publications in the period, design (1410 citations) and networks (1278 citations) topics gained more citations than did PDA (470 citations), resulting in a more significant impact on mobile computing research. Therefore, the diagram indicated that PDA was developed but remained an isolated topic in the period, whereas design and networks were important but rather undeveloped topics. The third period (2005-2009) was the first time that mobile computing, commerce and applications were displayed together on the fourth quadrant of the strategic diagram. Similar to mobile computing, mobile commerce and applications attained salient importance in both publication and citation counts. It is worth mentioning that although mobile computing research achieved profound importance in the number of publications and citations, mobile commerce research achieved higher impact in $\mathrm{h}$-index ${ }^{27}$ than did mobile computing. Two salient topics: "environments" and "intrinsic motivation," made comparatively high centrality and above-average density from 2005 to 2009. A reasonable explanation would be that location-based services and mobile/wireless technology are concerned with a variety of user environment states ${ }^{21}$ and motivations to adopt certain services and technology. In the fourth period (2010-2013), two topics associated with mobile computing arose in the first and fourth quadrants: ad-hoc networks and systems. Two additional topics -wireless communication and networks -- shifted to the second and third quadrants, resulting from a variety of mobile environments with different competing platforms that pose network availability challenges. It was also the period during which transition occurred from $3 \mathrm{G} / 3.5 \mathrm{G}$ to $4 \mathrm{G}$. Therefore, the major current research issues on the first quadrant during this period explained all of this variability in terms of environments, operations and performance.

The strategic diagrams seem to plot and reflect the issues confronted during the periods under consideration. The information provided by strategic diagrams entailed grouping topics according to the similarities in their centrality and density during certain periods of time. However, the analysis of strategic diagrams should include the metrics that allow researchers to evaluate the quantity, quality and impacts of the topics collectively contributed by related publications. As with conducting positioning in any market analysis field, the nature of positioning is not supposed to be static but rather dynamic. Researchers might retain the interpretation of strategic diagrams, unless some accountable metrics (e.g., accumulated citations and h-index) is simultaneously considered. 


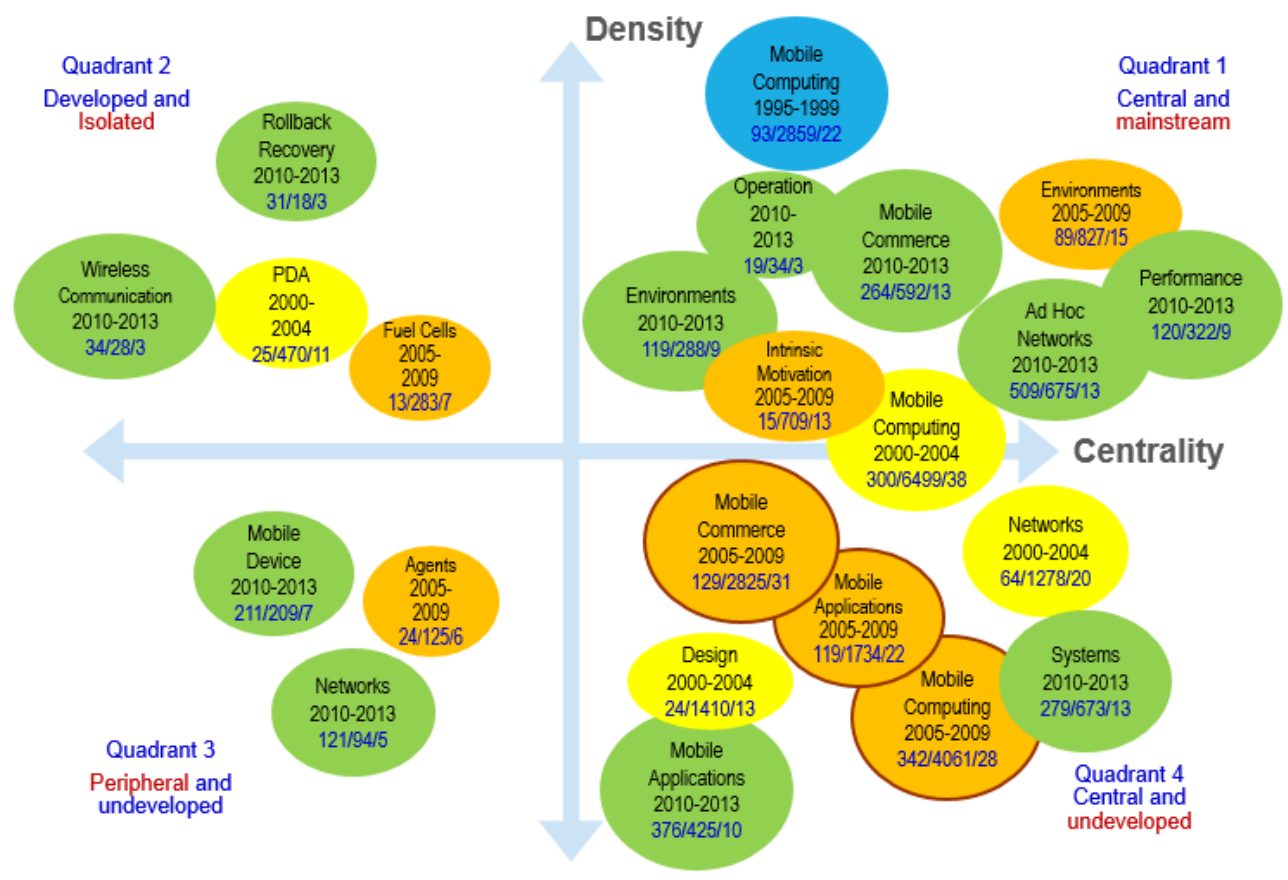

Figure 5. Strategic diagram: Major populated keywords over time

\subsection{Mapping Co-word Networks}

Although the strategic diagram provides an overview of keyword evolution, it is a bit difficult to perceive the co-word structures of each primary keyword. Hence, Table 1 presents the co-word structures inside the mobile computing cluster over time, which consist of comparatively strong linked networks of keywords. Systems, wireless communication, wireless networks, databases and ad-hoc network were popular topics in mobile computing research across four periods. As mobile communication technology advanced, new topics emerged. For instance, (mobile) ad-hoc network appeared since period 2 (2000-2004); wireless sensor networks came out since period three (2005-2009); the algorithms for sensor networks, virtual networks and energy efficiency issues in wireless communication appeared since period 4 (2010-2013). Recently, design issues of moving objects have become challenging due to different architectures of developing platforms and the variability of location-based services, which manifest as focal points of research. 
Table 1. The evolution of co-word structures of mobile computing

\begin{tabular}{|c|c|c|c|c|}
\hline \multirow{2}{*}{$\begin{array}{l}\text { Frequency } \\
\text { across } \\
\text { periods }\end{array}$} & \multicolumn{4}{|c|}{ Period } \\
\hline & 1995-1999 & 2000-2004 & 2005-2009 & 2010-2013 \\
\hline 4 & \multicolumn{4}{|c|}{ wireless communication } \\
\hline 4 & \multicolumn{3}{|c|}{ systems } & $\begin{array}{l}\text { distributed } \\
\text { systems }\end{array}$ \\
\hline 3 & \multicolumn{2}{|c|}{ wireless networks } & networks & $\begin{array}{l}\text { wireless } \\
\text { networks }\end{array}$ \\
\hline 3 & \multicolumn{3}{|c|}{ (mobile) databases } & - \\
\hline 3 & - & \multicolumn{3}{|c|}{ (mobile) ad hoc network } \\
\hline 2 & - & - & (wireless) s & isor network \\
\hline 2 & \multicolumn{2}{|c|}{ (mobile) communication } & - & - \\
\hline 1 & $\begin{array}{l}\text { wireless } \\
\text { LAN, } \\
\text { disconnected } \\
\text { operation, } \\
\text { distributed } \\
\text { algorithm, } \\
\text { file system, } \\
\text { quality of } \\
\text { service }\end{array}$ & $\begin{array}{l}\text { mobility } \\
\text { management, } \\
\text { broadcast } \\
\text { disks, mobile } \\
\text { agents, PCS }\end{array}$ & $\begin{array}{l}\text { intelligent } \\
\text { agents, } \\
\text { routing } \\
\text { protocols, } \\
\text { mobile } \\
\text { environment }\end{array}$ & $\begin{array}{l}\text { location-base } \\
\mathrm{d} \text { services, } \\
\text { moving } \\
\text { object, hand } \\
\text { off, } \\
\text { m-health, } \\
\text { pervasive } \\
\text { computing, } \\
\text { computer } \\
\text { applications }\end{array}$ \\
\hline
\end{tabular}

Both mobile commerce and application studies formed a focus since 2005 (Table 2). According to co-occurrence frequencies of keywords across periods, the research interests in mobile commerce centered on "(behavioral/purchasing) intention," "model" and "behavior," whereas the topics associated with mobile applications have changed with similar concepts but different terminologies.

Among recent topics in mobile commerce, "motivation," "services," "technology," "task-technology fit," "SMS" and "SEM" emerged. It appears that mobile commerce research sought cause-effect frameworks to explain why and how location-based services support user mobile communication needs; therefore, it is critical to gain insights into the factors of consumer behavior and motivation. The main topics in mobile applications from 2005 to 2009 were "mobile business," "mobile services," "SOFC," "design," "electrodes," and so forth. The focus in 2010 and 2013 extended to "trust models," "social networks," "recommender systems," "pervasive computing" and "ICT." Studies on the design of mobile devices began to shift to "smartphone," "mobile widgets" and the concepts associated with 
user interfaces, i.e. "tactile" and "liquid crystal display."

Table 2. The evolutions of co-word structures of mobile commerce and applications

\begin{tabular}{|c|c|c|c|c|}
\hline \multirow{3}{*}{$\begin{array}{l}\text { Frequency } \\
\text { across } \\
\text { periods }\end{array}$} & \multicolumn{2}{|c|}{ Mobile Commerce } & \multicolumn{2}{|c|}{ Mobile Application(s) } \\
\hline & \multicolumn{2}{|c|}{ Period } & \multicolumn{2}{|c|}{ Period } \\
\hline & 2005-2009 & $2010-2013$ & 2005-2009 & $2010-2013$ \\
\hline 2 & \multicolumn{2}{|c|}{$\begin{array}{c}\text { (behavioral/purchasing) } \\
\text { intention }\end{array}$} & - & - \\
\hline 2 & \multicolumn{2}{|c|}{ model } & - & - \\
\hline 2 & \multicolumn{2}{|c|}{ behavior } & - & - \\
\hline 1 & $\begin{array}{l}\text { business, } \\
\text { experience, } \\
\text { technology } \\
\text { acceptance, } \\
\text { cost, } \\
\text { framework, } \\
\text { information } \\
\text { systems, } \\
\text { loyalty }\end{array}$ & $\begin{array}{l}\text { motivation, } \\
\text { services, } \\
\text { technology, } \\
\text { task } \\
\text { technology } \\
\text { fit, short } \\
\text { message } \\
\text { service } \\
\text { (SMS), } \\
\text { consumer, } \\
\text { SEM }\end{array}$ & $\begin{array}{l}\text { mobile business, } \\
\text { mobile services, } \\
\text { SOFC, design, } \\
\text { electrodes, } \\
\text { infrastructure, } \\
\text { implementation, } \\
\text { architecture, } \\
\text { electro-chemical } \\
\text { characterization, } \\
\text { optimization, } \\
\text { video codec }\end{array}$ & $\begin{array}{l}\text { trust models, } \\
\text { social networks, } \\
\text { smartphone, } \\
\text { mobile web } \\
\text { applications, } \\
\text { mobile widget, } \\
\text { (tactile / liquid } \\
\text { crystal) display, } \\
\text { recommender } \\
\text { systems, } \\
\text { university, ICT, } \\
\text { space }\end{array}$ \\
\hline
\end{tabular}

\section{CONCLUSIONS}

This study is preliminary research on keyword use patterns in mobile computing, commerce and application research using co-word analysis. According to the evolution of co-word structures, mobile computing, commerce and applications are connected. Mobile computing technology and capability have led to the development of mobile commerce and applications. Another major finding is that the environments of mobile computing systems and applications have become more inclusive, as observed by the "environments" of co-word network grouping papers on mobile cloud computing ${ }^{12}$, mobile social networking applications ${ }^{13}$, and on mobile, cloud and big data computing ${ }^{11}$. Mobile computing and cloud computing will continue to transform mobile commerce and applications. However, the deployment of networks, both securely and authentically, is also important. If people can benefit from new mobile services, the well-being of ubiquitous computing still lies in the reasons for adopting mobile applications from both the supply and demand sides. The findings of co-word analysis corroborate the development of mobile computing, 
commerce and applications. The impacts of research topics can be assessed not only by the number of publications and citations, but also by the collective h-index scores contributed by different authors who have worked on the same topics over time. Until recently, applications of scientometrics to mobility research were scarce. By performing co-word analysis, this study clarifies and unveils knowledge conceptual structures regarding the inter-relationships among mobile computing, commerce and applications. However, the use of scientometrics remains an intriguing proposal in need of studies that explore social and intellectual networks depicting authors' social networks and citation networks.

\section{REFERENCES}

[1] C.C. Wang, and C.C. Chen, Electronic commerce research in latest decade: A literature review. International Journal of Electronic Commerce Studies, 1(1), p1-14, 2010.

[2] J. Whittaker, Creativity and conformity in science: Titles, keywords, and co-word analysis. Social Studies of Science, 19(3), p473-496, 1989. http://dx.doi.org/10.1177/030631289019003004.

[3] M. Callon, J. Courtial, and F. Laville, Co-word analysis as a tool for describing the network of interactions between basic and technological research: The case of polymer chemistry. Scientometrics, 22(1), p155-205, 1991. http:/dx.doi.org/10.1007/BF02019280.

[4] K. Boyack, B.N. Wylie, and G.S. Davidson, Domain visualization using VxInsight ${ }^{\circledR}$ for science and technology management. Journal of the American Society for Information Science and Technology, 53(9), p764-774, 2002. http://dx.doi.org/10.1002/asi.10066.

[5] I. Rafols, A. L. Porter, and L. Leydesdorff, Science overlay maps: A new tool for research policy and library management. Journal of the American Society for Information Science and Technology, 61(9), p1871-1887, 2010. http://dx.doi.org/10.1002/asi.21368.

[6] S.A. Morris, and B. van der Veer Martens, Mapping research specialties. Annual review of information science and technology, 42(1), p213-295, 2008. doi : http://dx.doi.org/10.1002/aris.2008.1440420113.

[7] L. Porter, and I. Rafols, Is science becoming more interdisciplinary? Measuring and mapping six research fields over time. Scientometrics, 81(3), p719-745, 2009. http://dx.doi.org/10.1007/s11192-008-2197-2.

[8] L. Porter, Technology foresight: Types and methods. International Journal of Foresight and Innovation Policy, 6(1/2/3), p36-45, 2010. http://dx.doi.org/10.1504/IJFIP.2010.032664.

[9] M. Satyanarayanan, Mobile computing: The next decade. ACM SIGMOBILE Mobile Computing and Communications Review, 15(2), p2-10, 2011. http://dx.doi.org/10.1145/2016598.2016600. 
[10] B. Andersson, Mobile Computing from a Developer's Perspective: A 10-Year Review, 1999-2008. Perspectives In Business Informatics Research 64, p220-233, 2010. http://dx.doi.org/10.1007/978-3-642-16101-8_18.

[11] J.C. Hsieh, A.H. Li, and C.C. Yang, Mobile, cloud, and big data computing: Contributions, challenges, and new directions in telecardiology. International Journal of Environmental Research and Public Health, $10 \quad$ (11), p6131-6153, 2013. http://dx.doi.org/10.3390/ijerph10116131.

[12] M. Shiraz, A. Gani, R.H. Khokhar, and R. Buyya, A review on distributed application processing frameworks in smart mobile devices for mobile cloud computing. IEEE Communications Surveys and Tutorials, 15(3), p1294-1313, 2013. http://dx.doi.org/ 10.1109/SURV.2012.111412.00045.

[13] P. Bellavista, R. Montanari, and S.K. Das, Mobile social networking middleware: A survey. Pervasive and Mobile Computing, 9(4), p437-453, 2013. http://dx.doi.org/10.1016/j.pmcj.2013.03.001.

[14] U. Varshney, and R. Vetter, Mobile commerce: framework, applications and networking support. Mobile Networks and Applications, 7(3), p185-198, 2002. http://dx.doi.org/ 10.1023/A:1014570512129.

[15] E. Mennecke, and T.J. Strader, Mobile commerce: Technology, theory, and applications. London: IDEA Group Publishing, 2003.

[16] E.W. Ngai, and A. Gunasekaran, A review for mobile commerce research and applications. Decision Support Systems, 43(1), p3-15, 2007. http://dx.doi.org/10.1016/j.dss.2005.05.003.

[17] K. Varnali, and A. Toker, Mobile marketing research: The-state-of-the-art. International Journal of Information Management, 30(2), p144-151, 2010. http://dx.doi.org/ 10.1016/j.ijinfomgt.2009.08.009.

[18] A. Holzer, and J. Ondrus, Trends in Mobile Application Development. Social Informatics and Telecommunications Engineering, 12, p55-64, 2009. http://dx.doi.org/10.1007/978-3-642-03569-2_6.

[19] A. Holzer, and J. Ondrus, Mobile application market: A developer's perspective. Telematics and Informatics, 28(1), p22-31, 2011. http://dx.doi.org/10.1016/j.tele.2010.05.006.

[20] G. Damianos, and D. Economou. Development platforms for mobile applications: status and trends. IEEE Software, 28(1), p77-86, 2011. http://dx.doi.org/10.1109/MS.2010.155.

[21] C. Emmanouilidis, R.A. Koutsiamanis, and A. Tasidou, Mobile guides: Taxonomy of architectures, context awareness, technologies and applications. Journal of Network and Computer Applications, 36(1), p103-125, 2013. http://dx.doi.org/10.1016/j.jnca.2012.04.007.

[22] E. Garfield, Scientography: Mapping the tracks of science. Current 
Contents: Social \& Behavioural Sciences, 7(45), p5-10, 1994.

[23] J. Law, S. Bauin, and J.P. Courtial, Policy and the mapping of scientific change: A co-word analysis of research into environmental acidification. Scientometrics, 14(3), p251-264, 1988. http://dx.doi.org/10.1007/BF02020078.

[24] M. Callon, J. Courtial, W. Turner, and S. Bauin, From translations to problematic networks: An introduction to co-word analysis. Social Science Information, 22(2), p191-235, 1983. http://dx.doi.org/10.1177/053901883022002003.

[25] M.J. Cobo, A.G. López-Herrera, E. Herrera-Viedma, and F. Herrera, SciMAT: A new science mapping analysis software tool. Journal of the American Society for Information Science and Technology, 63(8), p1609-1630, 2012. http://dx.doi.org/10.1002/asi.22688.

[26] N. Coulter, I. Monarch, and S. Konda. Software engineering as seen through its research literature: A study in co-word analysis. Journal of the American Society for Information Science, 49(13), p1206-1223, 1998.

http://dx.doi.org/10.1002/(SICI)1097-4571(1998)49:13<1206::AID-AS I7>3.0.CO;2-F.

[27] J. Hirsch, An index to quantify an individual's scientific research output. Proceedings of the National Academy of Sciences, 102(46), p16569-16572, 2005. http://dx.doi.org/10.1073/pnas.0507655102. 
